\title{
Research on Rapid Evaluation of Rock Mass Quality Based on Ultrasonic Borehole Imaging Technology and Fractal Method
}

\author{
Yuezheng Zhang $\mathbb{D D}^{1,2}$ Hongguang Ji, ${ }^{1,2}$ Wenguang $\mathrm{Li}^{3}{ }^{3}$ and Kuikui Hou ${ }^{4}$ \\ ${ }^{1}$ University of Science \& Technology Beijing, Beijing 100083, China \\ ${ }^{2}$ Beijing Key Laboratory of Urban Underground Space Engineering, Beijing 100083, China \\ ${ }^{3}$ Sanshandao Gold Mine of Shandong Gold Mining (Laizhou) Co. Ltd., Laizhou, Shandong 261442, China \\ ${ }^{4}$ Laboratory on Deep Mining of Shandong Gold Group Co. Ltd., Laizhou, Shandong 261442, China \\ Correspondence should be addressed to Yuezheng Zhang; yuezheng20053660@163.com
}

Received 15 April 2021; Accepted 10 May 2021; Published 19 May 2021

Academic Editor: Xianjie Hao

Copyright $\odot 2021$ Yuezheng Zhang et al. This is an open access article distributed under the Creative Commons Attribution License, which permits unrestricted use, distribution, and reproduction in any medium, provided the original work is properly cited.

\begin{abstract}
The distribution of discontinuities in the deep stratigraphic rock mass is random and irregular, and the spatial distribution has statistical self-similarity, which can be analyzed by fractal theory. The borehole wall image obtained based on the ultrasonic borehole imaging technology can clearly reflect the rich structural surface information such as the inclination, density, and crack width of the structural surface in the rock mass. Due to its inherent fractal characteristics, the fractal box dimension of the hole wall image can be used to describe the complexity of the structural surface. In the study, the fractal box dimension of the hole wall image and the RQD value of the rock mass are compared, and it is found that there is a linear correlation between the two. Therefore, the rock quality can be evaluated according to the fractal box dimension value of the hole wall image. Finally, a rapid quantitative evaluation method for rock mass quality classification is established based on ultrasonic borehole imaging technology and fractal method.
\end{abstract}

\section{Introduction}

As the depth of resource extraction increases, human engineering activities are gradually developing into the deep strata. Deep stratum is a complex geological body composed of multiple media and multiphase physical and mechanical fields. Under the combined action of in situ stress, high ground temperature, high permeability pressure, and strong disturbance of deep space development and construction, it may cause sudden dynamic disasters during the excavation of underground engineering, such as rock bursts, water inrush, faults $[1,2]$, dislocation, and partial collapse. Accurate detection and evaluation of engineering rock mass quality is the basis for predicting and controlling the risks of deep underground engineering as well as the key basis for site selection, design, and construction of deep engineering $[3,4]$.

RQD indicators are often used in evaluating rock quality indicators [5], which are widely used in rock mass stability evaluations such as water conservancy and hydropower, mines, underground engineering, and traffic engineering. During the engineering survey, the drilling method is used to expose the stratum characteristics of the engineering area, and the rock quality is evaluated by the integrity of the core. However, there are often deviations in drilling methods in actual operations, especially in deep formations. The current drilling depth has exceeded $2000 \mathrm{~m}$, and the rock is affected by its own strength, bit strength, long-distance lifting, and workers' coring habits during the drilling process. In addition, the scientificity and practicability of geological cataloging data are greatly affected by the engineering experience and sense of responsibility of the cataloging personnel, resulting in a certain gap between the RQD value of the rock and the actual one [6]. Therefore, it is one of the most direct methods to observe the in situ state of the rock mass, which can judge the quality of the rock by observing the condition of the core and by directly observing the characteristics of the hole wall. The imaging logging images 
can be used to obtain intuitive and accurate information about the rock formation properties of the borehole wall, and the data of acoustic imaging, video, imaging, and geological data can be compared, and the high-precision information of the rock formations obtained by comprehensive interpretation can be made up for the missing data and information caused by the lack of core drilling [7]. Qin and Cao used borehole ultrasonic imaging testing technology to quantitatively analyze the integrity of the rock mass exposed by the borehole as an important basic data for regional stability analysis, engineering rock mass quality classification, and engineering design [8]; Wang et al. carried out ultrasonic borehole imaging logging work in Pulang Copper Mine and, based on the monitoring data, interpreted the occurrence of the structural planes of the four boreholes, the degree of crack opening, and the integrity of the borehole rock mass [9]; Wang et al. carried out research on the extraction method of structural plane parameters based on borehole images to obtain information regarding plane inclination, dip, and gap width [10]. This technology is increasingly widely used in engineering, but the analysis is mainly in the manual analysis stage, resulting in large discrete analysis conclusions, time-consuming and laborious, and it is urgent to establish an accurate and fast intelligent automatic analysis method.

Therefore, it is an important breakthrough to perform digital image processing on high-precision digital borehole wall images acquired by ultrasonic drilling imaging technology to accurately and quickly obtain rock quality characteristics in deep formations. In this paper, the fractal method is used to analyze the hole wall image, and the correlation between the dimensional characteristics of the hole wall image box and the rock quality is studied, and then, a rapid and accurate rock quality analysis method based on borehole imaging technology is established [11].

\section{Experimental}

HIRAT (High-Resolution Acoustic Televiewer) of the borehole imaging system of Robertson Geologging, UK is used. The device has high resolution and accurate azimuth determination, which is especially suitable for determining the detailed situation of rock fracture tendency, inclination, and fracture development. High-resolution acoustic television is a device designed to provide qualitative images for borehole walls. Due to the use of ultrasound instead of visible light, it can work in turbid well water, expanding its application range [8].

The working principle of the equipment: the resonator of the monitoring probe is immersed in the oil and generates an ultrasonic pulse $(0.5 \sim 1.5 \mathrm{MHz})$. The ultrasonic pulse passes through the oil first, then passes through the wall of the acoustic chamber, and then penetrates the liquid in the borehole and is reflected by the wall of the borehole. The reflected energy is sensed by the same sensor, which records the amplitude and transmission time of the return pulse. The amplitude of the return pulse is a function of the acoustic reflection ability of the hole wall. The energy reflected by the sound wave hitting the hole wall is used to obtain the crack distribution of the hole wall (if the normal surface energy returns to the sensor, a strong reflection will be recorded. If there are cracks or other structures on the hole wall, the energy will be dispersed and a weak reflection will be recorded). Although the thicker drilling mud will cause a certain amount of scattering of the sound beam, it can be used well in dirty or turbid environments due to the use of ultrasonic waves instead of visible light [9].

At the same time, in order to ensure that the position of the captured image can be accurately identified, there is a device inside the acoustic TV that provides positioning images for the wall of the borehole. There is an integrated system of a magnetometer and a set of three-way orthogonal inclinometer in the acoustic TV. The magnetometer detects the earth's magnetic field and derives the direction of the earth's magnetic field and the north pole of the magnetic field. The inclinometer can calculate the inclination direction of the hole wall, thus providing a complete three-dimensional survey instrument $[9,12]$.

\section{Results and Discussion}

3.1. Ultrasonic Drilling Imaging Method. The borehole ultrasonic imaging system has the characteristics of high resolution and high precision and can provide a large amount of useful information needed for basic engineering analysis, so it has been widely used in geological surveys [12]. The engineering background in this article is the exploration hole of the auxiliary shaft in the Xiling mining area of Sanshandao Gold Mine, and the hole depth is $-2017 \mathrm{~m}$. The ultrasonic borehole imaging test is mainly carried out for the deep formation, and the borehole wall images from the depth of $-874 \mathrm{~m}$ and $-1635 \mathrm{~m}$ are obtained. The quality of the rock wall in the deeper borehole is poor, and the probe is difficult to pass. The coring results for this drill hole show that the lithology is mainly granite, a kind of igneous rock. Although it is the same lithology, there are certain differences in the internal composition of the granite rock as the depth changes. The vertical and horizontal distribution of the structural planes inside the rock mass causes the difference in the quality of the rock mass, as shown in Figures 1 and 2 .

Through the field test, the interpretation image of the borehole was obtained, as shown in Figures 1-3. Because substances of different integrity and strength have different reflection capabilities for ultrasonic waves, dark black represents the more broken and lower-strength part of the rock mass, and light yellow represents the more complete and higher-strength part of the rock mass. Ultrasonic borehole imaging is basically consistent with the stratum features revealed by geological exploration, and it intuitively reveals the stratum rock mass structure through which the borehole penetrates the strata. Compared with the core photos one by one, it is found that the hole wall images corresponding to the broken zone core, vertical joints, high-angle joints, and cake cores have significant characteristics, which provide detailed and reliable basic data for the subsequent rapid and accurate analysis of the quality of the rock mass. 

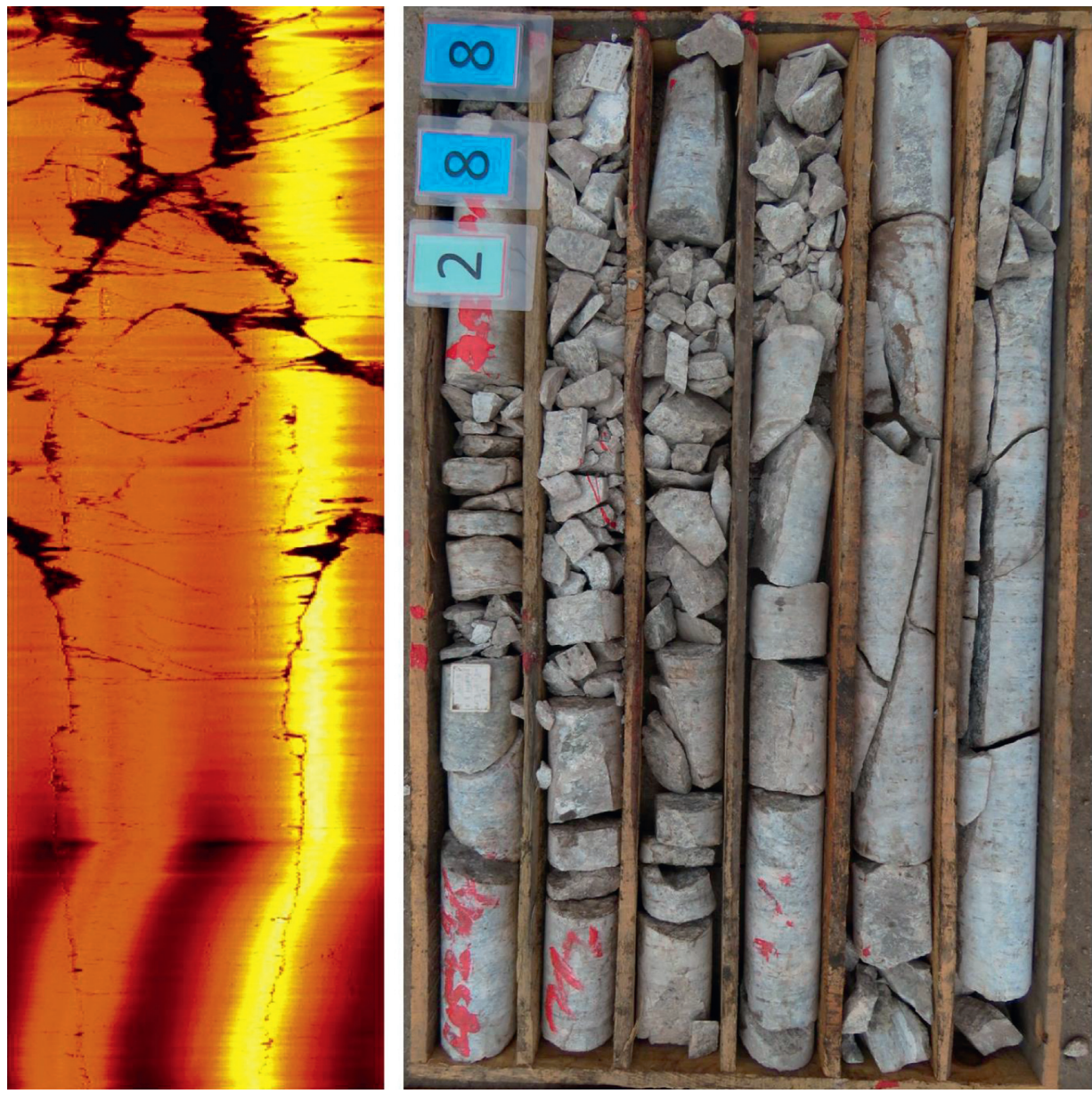

FIgURE 1: Images of drill core and hole wall (-1048 to $-1058 \mathrm{~m})$.

3.2. Rock Fractal Characteristics and Fractal Box Dimension. The fractured structural surfaces such as joints and faults developed in the rock mass are the root cause of the discontinuity of the rock mass medium. The existence of structural planes not only destroys the integrity of the rock mass but also directly affects the mechanical properties and failure modes of the rock mass. Due to the irregularity and discontinuity of the structural plane space and the complexity of the structural plane network formed, the distribution of rock mass structural planes is random and in a disorderly state. It is difficult to use traditional Euclidean geometry and Newtonian continuum mechanics. The existing research results show that the distribution of rock mass structural planes has statistical self-similarity and fractal characteristics, so it can be studied by fractal theory [13].

The spatial distribution of joints inside the rock mass is mostly self-similar. Self-similarity refers to the statistical similarity between the part and the whole in terms of form, function, and information. When the geometric size of the fractal object is appropriately enlarged or reduced, the whole structure has not changed $[14,15]$. To a certain extent, the fractal dimension of the rock mass contains abundant structural surface information inside the rock mass, and the quality of the rock mass can be evaluated according to the fractal dimension. The borehole wall image obtained by ultrasonic borehole imaging technology contains rich rock structural surface information, such as fracture zone, horizontal joints, and vertical high-angle joints. The fractal characteristics of the bore wall image can be directly analyzed for evaluation of the quality of the rock mass [16].

The most basic parameter for fractal theory to characterize the geometric complexity is the fractal dimension. Dimension is one of the elements describing the fractal set. It is the basic invariant of the graph, including similarity dimension, Hausdorff dimension, and box dimension, all of which can be scored and quantitatively describe the complexity of fractal set. Among them, the fractal box dimension is easier to obtain and is often used in mathematical calculations and experimental measurements, so this paper uses the box dimension to analyze the data $[17,18]$.

Perform fractal analysis on the image, place the image on the image plane to form an image intensity surface [19], and then divide the plane below with a grid, and then, the different box dimensions can be obtained by the following formula: 

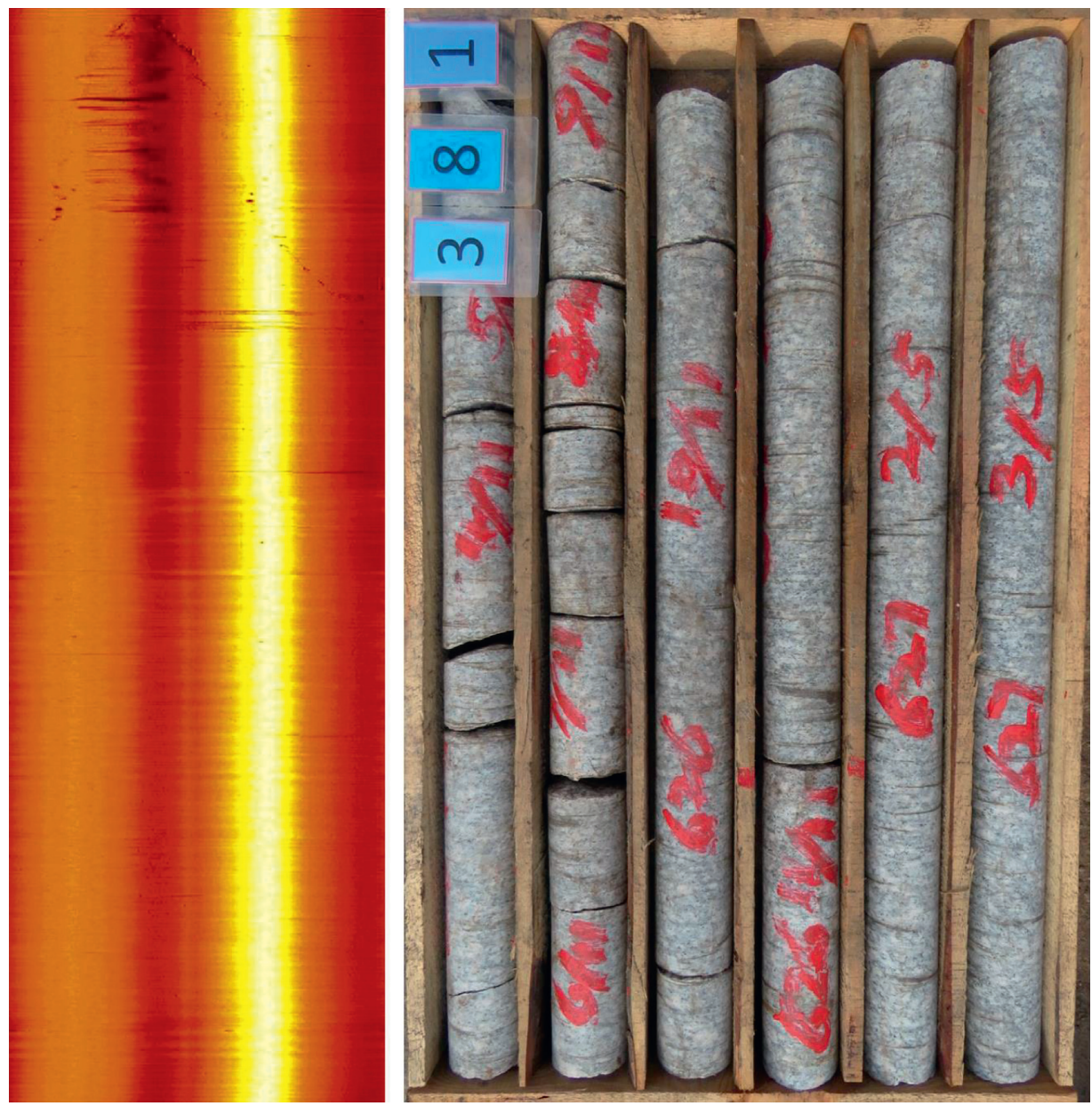

FIgURE 2: Images of drill core and hole wall $(-1472.36 \mathrm{~m}$ to $-1476.96 \mathrm{~m})$.
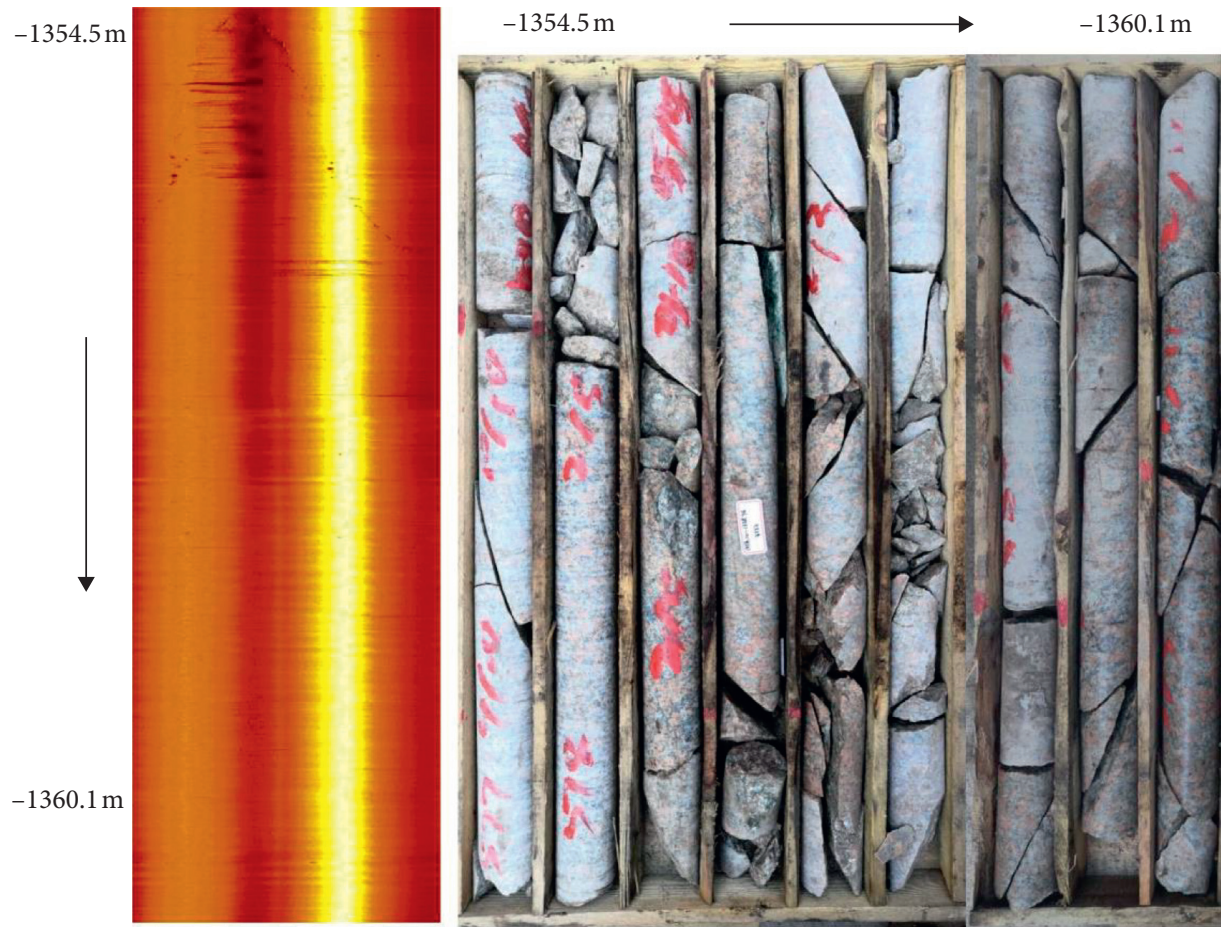

Figure 3: $-1354.5 \mathrm{~m} \sim-1360.1 \mathrm{~m}$ depth range core and borehole imaging map. 


$$
\operatorname{Dim}_{B} F=\lim _{\delta \longrightarrow 0} \frac{\operatorname{InN}(F, \delta)}{\operatorname{In}(1 / \delta)} .
$$

The box dimension calculation process uses MATLAB software [20].

\subsection{Relationship between Fractal Box Dimension and Rock Quality}

3.3.1. Select the Size Analysis Method. The borehole diameter of the ultrasonic borehole imaging test section is $95 \mathrm{~mm}$, the perimeter of the aperture is about $300 \mathrm{~mm}$, and the longitudinal depth of each image is $5600 \mathrm{~mm}$, divided into 16 equal parts. The actual size of each small image is $300 \mathrm{~mm} \times 350 \mathrm{~mm}$ (width $\times$ height). In the calculation process, MATLAB software is used for image segmentation and box dimension calculation. First, the hole wall histogram is made into a $256 \times 4096$ pixel image, and then, it is equally divided into 16 sample images longitudinally. The pixel size of each sample image is $256 \times 256$, which represents the actual hole wall size of $300 \mathrm{~mm} \times 350 \mathrm{~mm}$. The calculation of the fractal box dimension uses the MATLAB algorithm provided by the network to calculate 16 samples.

In the analysis process, to ensure that the examples are representative, on the one hand, the hole wall histogram should ensure good imaging quality; on the other hand, it should cover complete, moderately complete, poorly complete, and broken rock masses of various quality levels. In this study, the hole wall images and cores in the depth range of $-1354.5 \mathrm{~m} \sim-1360.1 \mathrm{~m}$ were selected for analysis. As shown in Figure 3, the left side is the hole wall column diagram, and the well-developed joints are clearly visible in the hole wall diagram; the right side is the drilled core diagram, with a complete core and broken stones cut by the joints. The cores in this depth range basically cover various quality rock masses ranging from intact to broken, with good representativeness [21].

\subsubsection{Intuitive Observation and Analysis of Feature} Relationships. Using the fractal box dimension calculation method, the calculation is carried out for 16 sample images of the depth range, and the image fractal box dimension value of each sample image is obtained, as shown in Figure 4. Because the rock structural surface has fractal characteristics in a statistical sense, the reflection of joints on the borehole imaging map increases the complexity of the image, and this complexity has self-similarity, so the fractal box dimension of the image indirectly reflects the joints. The higher fractal box dimension is associated with the more developed cracks [22]. The calculation results show that the lower the degree of joint development, the lower the value of the fractal box dimension and the more complete the rock, as shown in the samples $1 \#, 2 \#$, and 13\#; the more developed the joints and fissures, the more complex the hole wall image, the higher the value of the fractal box dimension, and the more broken the rock, as shown in the 9\# and 10\# samples.
The calculation result of the fractal box dimension for the borehole wall image shows that the rock quality is closely related to the development degree and shape of the internal structural plane of the rock mass. The complexity of the image through the hole wall also reflects the characteristics of joint and fissure development. The fractal box dimension of the hole wall image can be used directly to describe the complexity of the structural surface, and then, the rock quality can be characterized. There is a certain quantitative relationship between the fractal characteristics of the hole wall image and the rock quality directly [23].

3.3.3. $R Q D$ and Fractal Box Dimension. The RQD value represents the complete characteristics of the rock and is the most widely used in international rock quality evaluation [24]. According to the RQD value, rock quality is generally divided into five grades: very poor (0 25), poor (25 50), fair (50 75), good (75 90), and very good (90 100). In order to quantitatively analyze the relationship between fractal dimension and rock quality, according to the RQD calculation principle, the corresponding RQD value of the core section is calculated for each borehole wall sample diagram, as shown in Table 1 .

According to Table 1, the relationship between the RQD value and the fractal box dimension $\mathrm{Db}$ is drawn, as shown in Figure 5, and it is found that, with the increase of the RQD value, the fractal box dimension of the hole wall image decreases, and a good linear fitting relationship exists between the two [25]. It can be seen that the fractal dimension of borehole wall images that can characterize the distribution of rock mass structural planes not only reflects the engineering geological characteristics of the rock mass but also reflects the different characteristics of rock mass quality. The fractal dimension of rock mass structural plane distribution can be used as a grading index of rock mass quality.

The study found that the relationship between the borehole wall image, the fractal box dimension value, and the rock quality RQD obtained from the abovementioned engineering survey holes can be given according to the corresponding relationship between the fractal box dimension and the rock mass quality classification. There is a close relation between the drilling fractal dimension and engineering rock mass classification. According to this relationship, the rock mass quality under the same drilling conditions in this project area can be quickly classified according to the fractal box dimension of the hole wall image feature. Table 2 shows the quantitative correspondence between rock mass quality classification and fractal dimension in the survey borehole.

In this study, the use of fractal theory to evaluate rock mass quality is a quantitative study of rock mechanics. The image fractal dimension of the borehole wall directly reflects the structural surface distribution characteristics of the rock mass and indirectly reflects the engineering geological characteristics of the rock mass, such as the degree of fracture, the degree of disturbance, the strength of the rock mass, the rock alteration, and the water conductivity of the 


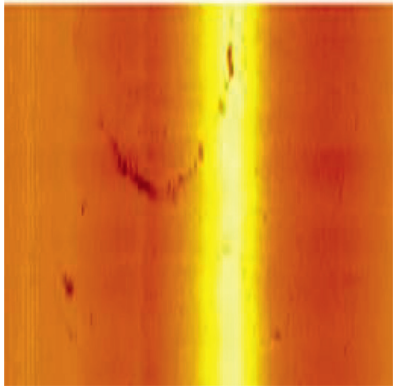

(a)

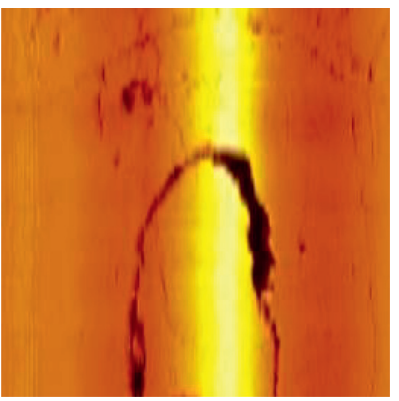

(e)

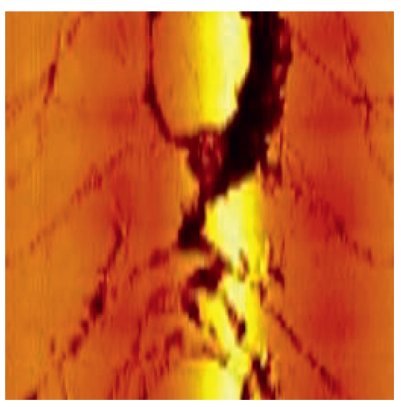

(i)

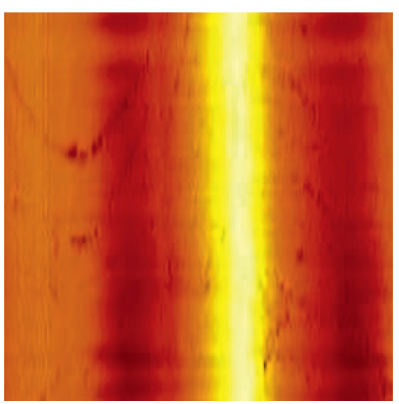

(m)

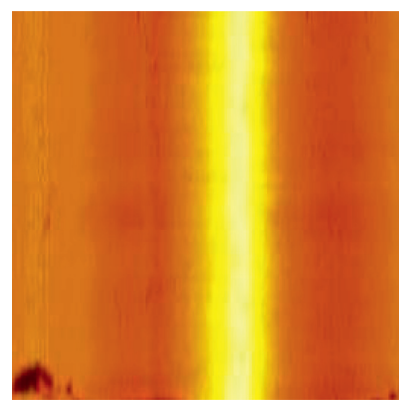

(b)

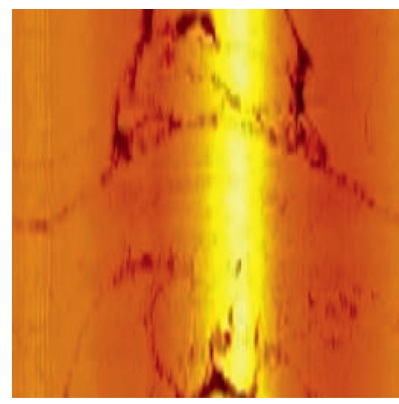

(f)

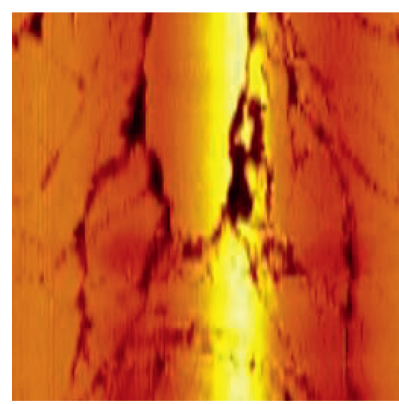

(j)

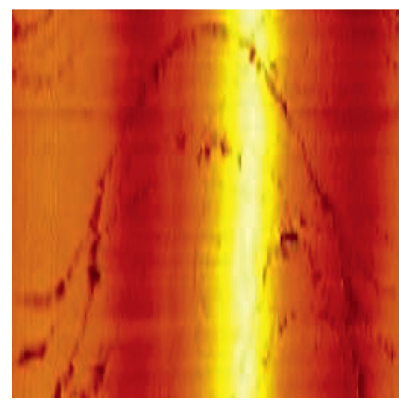

(n)

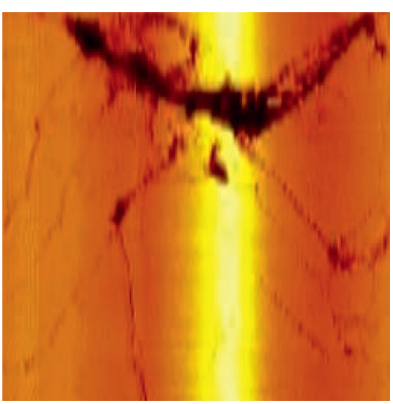

(c)

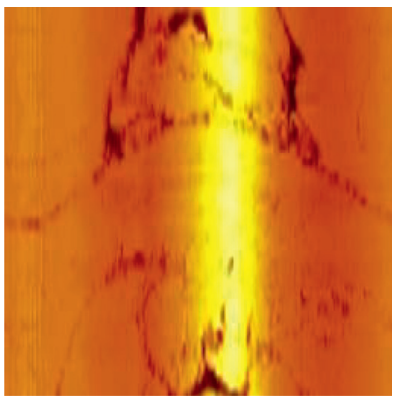

(g)

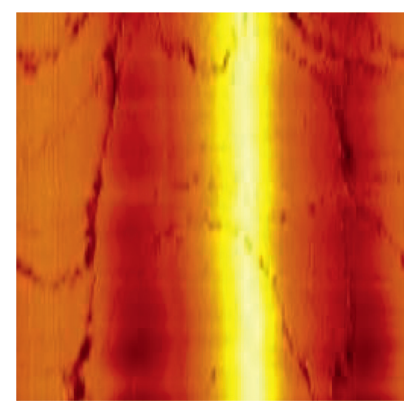

(k)

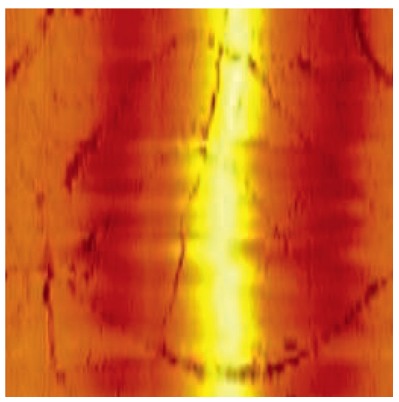

(o)

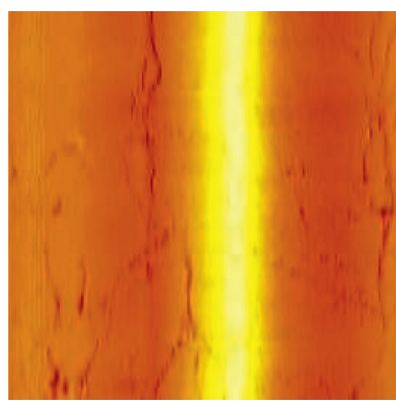

(d)

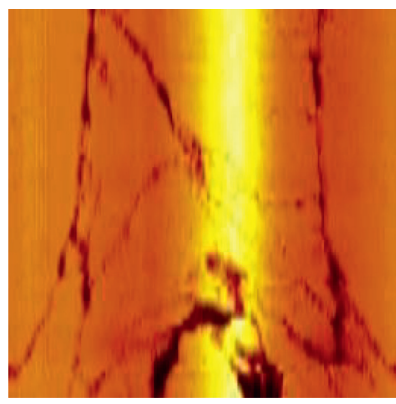

(h)

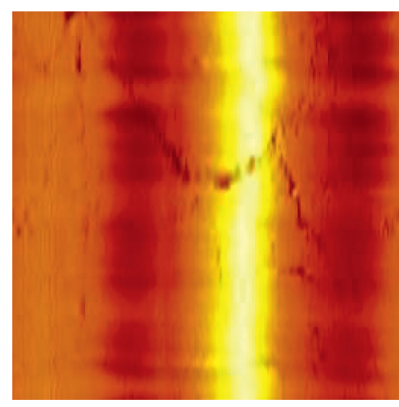

(l)

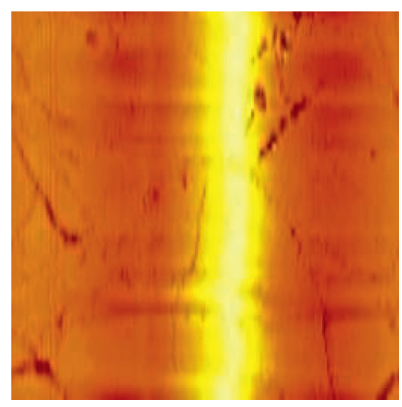

(p)

Figure 4: Sample image and its fractal box dimension Db value. (a) 2.0469. (b) 2.0382. (c) 2.0917. (d) 2.0379. (e) 2.0620. (f) 2.1073. (g) 2.0773. (h) 2.0960. (i) 2.1700. (j) 2.1599. (k) 2.0767. (l) 2.0747. (m) 2.0649. (n) 2.0995. (o) 2.0802. (p) 2.0463.

rock mass. This shows that the fractal dimension of the hole wall image can be used as a classification index to measure the quality of the rock mass [26].

This paper calculates and analyzes the rock quality grading characteristic value based on the fractal box dimension under the background of the engineering case. Through this method, the formation rock mass in front of the project can be quickly evaluated based on the ultrasonic drilling imaging technology in the drilling process under certain engineering conditions. This method has high research value and also provides convenience for engineering exploration. In the preliminary survey of the project or the advanced construction of the construction, the rapid and accurate evaluation of the quality of the formation rock mass can be realized without the need to take the core so that the construction period is greatly shortened.

However, in the acquisition process of ultrasonic borehole imaging for different engineering environments, 
TABLe 1: RQD value and fractal box dimension $\mathrm{Db}$ value of drilling at different depths.

\begin{tabular}{lccc}
\hline Sample number & Depth range & RQD & Fractal dimension \\
\hline 1 & $-1354.50 \sim-1354.85$ & 92.3 & 2.047 \\
2 & $-1354.85 \sim-1355.20$ & 100 & 2.038 \\
3 & $-1355.20 \sim-1355.55$ & 54.1 & 2.092 \\
4 & $-1355.55 \sim-1355.90$ & 93.9 & 2.038 \\
5 & $-1355.90 \sim-1356.25$ & 76.1 & 2.062 \\
6 & $-1356.25 \sim-1356.60$ & 61.3 & 2.107 \\
7 & $-1356.60 \sim-1356.95$ & 83.4 & 2.077 \\
8 & $-1356.95 \sim-1357.30$ & 41 & 2.096 \\
9 & $-1357.30 \sim-1357.65$ & 19.7 & 2.17 \\
10 & $-1357.65 \sim-1358.00$ & 0 & 2.16 \\
11 & $-1358.00 \sim-1358.35$ & 73.7 & 2.077 \\
12 & $-1358.35 \sim-1358.70$ & 70.9 & 2.075 \\
13 & $-1358.70 \sim-1359.05$ & 71.1 & 2.065 \\
14 & $-1359.05 \sim-1359.40$ & 54.7 & 2.099 \\
15 & $-1359.40 \sim-1359.75$ & 82.3 & 2.08 \\
16 & $-1359.75 \sim-1360.10$ & 92 & 2.046 \\
\hline
\end{tabular}

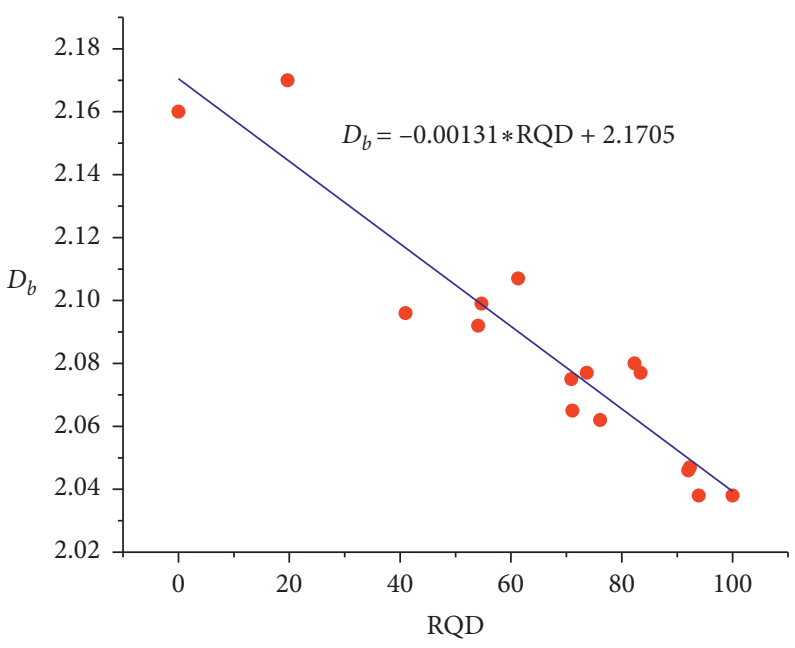

FIgURE 5: RQD value and fractal box dimension $\mathrm{Db}$ linear fitting relationship diagram.

TABLE 2: Rock mass quality classification according to the fractal box dimension $\mathrm{D}$ of the hole wall image

\begin{tabular}{llllll}
\hline$D$ & $<2.0526$ & $2.0526 \sim 2.0723$ & $2.0723 \sim 2.105$ & $2.105 \sim 2.1378$ & $>2.1378$ \\
\hline Rock quality & Very good & Good & General & Poor & Very poor \\
\hline
\end{tabular}

it will also be affected by factors such as borehole slurry, stratum lithology, human operation, and data interpretation, resulting in differences in borehole wall imaging quality, and the image fractal dimension of rock mass quality will also produce differences. At the same time, changes in stratum structure or different lithology will also affect the imaging effect of the hole wall. This article only studies a single lithology granite formation, which has good applicability. The imaging characteristics of sedimentary rocks with significant lithological changes need to be further studied. Therefore, in the actual application process of using the hole wall image fractal box dimension to evaluate rock mass quality, it is also necessary to define the fractal box dimension standard for rock quality classification according to the actual conditions of the engineering site.

\section{Conclusion}

(1) The actual measurement results show that the quality of deep hole walls in hard rock formations can be clearly obtained by ultrasonic drilling imaging technology, which overcomes the problem of difficult optical imaging caused by slurry during mud 
wall drilling and can obtain a large number of effective drilling holes. Visualized quantitative data of borehole rock mass, such as structural plane inclination, density and open crack width, etc.

(2) The rock mass in the stratum is cut into complex structures by structural planes. The structural planes such as joints and cracks have self-similarity, which makes the distribution of discontinuous planes in the rock mass have good fractal characteristics. Fractal theory can be used to study the structural characteristics of rock masses.

(3) Due to the fractal characteristics of structural plane distribution, there is a close correlation between the fractal box dimension value of the hole wall image obtained by ultrasonic borehole imaging technology and the rock mass, and there is a linear relationship between the fractal box dimension value and RQD. The fractal box dimension can be used to quickly and accurately evaluate the quality of the formation rock mass.

(4) Combined with ultrasonic drilling imaging technology, the fractal dimension of the hole wall image is used as a simple and practical quantitative method for rock mass quality classification. In the application process, it is also necessary to consider the geological environment and imaging quality faced by the actual project to formulate the corresponding division parameter standards.

\section{Data Availability}

The data used to support the findings of this study are available from the corresponding author upon request.

\section{Conflicts of Interest}

The authors declare that they have no conflicts of interest.

\section{References}

[1] Z. Q. Liu, Z. Y. Song, H. G. Ji et al., "Construction mode and key technology of mining shaft engineering for deep mineral resources," Journal of China Coal Society, vol. 46, no. 3, pp. 826-845, 2021.

[2] X. Hao, W. Du, Y. Zhao et al., "Dynamic tensile behaviour and crack propagation of coal under coupled static-dynamic loading," International Journal of Mining Science and Technology, vol. 30, no. 5, pp. 659-668, 2020.

[3] J. F. Lou, F. Q. Gao, J. H. Yang et al., "Characteristics of evolution of mining-induced stress field in the longwall panel: insights from physical modeling," International Journal of Coal Science and Technology, 2021.

[4] X. Hao, Y. Wei, K. Yang et al., "Anisotropy of crack initiation strength and damage strength of coal reservoirs," Petroleum Exploration and Development, vol. 48, no. 1, pp. 243-255, 2021.

[5] L. M. Xu, Q. Wang, J. P. Chen et al., "Study of correlation between fractal dimension and RQD of three-dimensional jointed rock mass," Chinese Journal of Rock Mechanics and Engineering, vol. 30, no. S1, pp. 2667-2674, 2011.
[6] F. J. Zhou, J. P. Chen, and L. M. Xu, "Study of rock masses quality evaluation based on 3D fractal dimension of rock discontinuity distribution," Rock and Soil Mechanics, vol. 33, no. 8, pp. 2315-2322, 2012.

[7] C. Y. Wang and K. T. Law, "Review of borehole camera technology," Chinese Journal of Rock Mechanics and Engineering, vol. 24, no. 19, pp. 42-50, 2005.

[8] X. S. Qing and H. Cao, "Analysis of rock mass integrity based on borehole ultrasonic imaging testing technology," Nonferrous Metals Engineering, vol. 7, no. 1, pp. 82-86, 2017.

[9] P. Wang, X. L. Feng, Y. S. Cai et al., "Distribution of borehole joints by borehole ultrasonic technology in Pulang copper deposit," Mining\&Metallurgy, vol. 28, no. 2, pp. 1-5, 2019.

[10] J. C. Wang, D. X. Tao, Y. Q. Huang et al., "Borehole imaging method based on ultrasonic synthetic aperture technology," Rock and Soil Mechanics, vol. 40, no. S1, pp. 557-564, 2019.

[11] X. Yang, Z. Q. Yang, Q. Gao et al., "Block size prediction of rock masses based on joint network simulation and fractal theory," Journal of Taiyuan University of Technology, vol. 46, no. 3, pp. 318-322, 2015.

[12] Y. Y. Shi, Y. J. Shang, Y. C. Sun et al., "Applications of acoustic borehole televiewer in geotechnical investigation," Geotechnical Investigation \& Surveying, vol. 38, no. 8, pp. 82-87+92, 2010.

[13] J. C. Wang, C. Y. Wang, S. Hu et al., "A new method for extraction of parameters of structural surface in borehole images," Rock and Soil Mechanics, vol. 38, no. 10, pp. 30743080, 2017.

[14] K. Zhang, K. Li, R. Bao, W. Y. Wu, and X. H. Liu, "Trace of the specific features of the en- tire destruction process of the rock bridge," Journal of Safety and Environment, vol. 20, no. 2, pp. 473-481, 2020.

[15] J. Xu, Q. Lu, X. Wu, and D. Liu, “The fractal characteristics of the pore and development of briquettes with different coal particle sizes," Journal of Chongqing University, vol. 34, no. 9, pp. 81-89, 2011.

[16] J. F. Lian, N. Q. Shen, and J. K. Zhang, "Application research on fractal theory in rockmass quality evaluation," Chinese Journal of Rock Mechanics and Engineering, vol. 20, no. S1, pp. 1695-1698, 2001.

[17] "The fractal characteristics of jointed rock mass and its engineering geology significance," Journal of Engineering Geology, vol. 1, no. 2, pp. 14-23, 1993.

[18] M.-z. Gao, J.-g. Zhang, S.-w. Li, M. Wang, Y.-w. Wang, and P.-f. Cui, "Calculating changes in fractal dimension of surface cracks to quantify how the dynamic loading rate affects rock failure in deep mining," Journal of Central South University, vol. 27, no. 10, pp. 3013-3024, 2020.

[19] Y. Z. Zhang, H. G. Ji, P. Xiang et al., "Analysis of precursor of rock burst based on the fractal characteristics of the mine borehole strain observation data," Chinese Journal of Rock Mechanics and Engineering, vol. 35, no. S1, pp. 3222-3231, 2016.

[20] https://blog.csdn.net/lhhzbmh/article/details/87649134.

[21] T. Y. Wang, C. Y. Wang, X. J. Zheng et al., "Study on the morphology description method of borehole wall profile line and its application based on borehole camera technology," Chinese Journal of Rock Mechanics and Engineering, vol. 39, no. S2, pp. 3412-3420, 2020.

[22] S. X. Liu, J. Xing, X. Zheng et al., “Zonal damage information and critical failure identification of CT images of rock under triaxial compression," Chinese Journal of Geotechnical Engineering, vol. 43, no. 3, pp. 432-438, 2021. 
[23] C. Zhang, W. D. Song, and J. X. Fu, "Study on fractal theory in rock mass quality evaluation," Mining R\&D, vol. 40, no. 2, pp. 71-75, 2020.

[24] W. Xu, X. L. Hu, L. Huang et al., "Research on RQD of rock mass calculated by three-dimensional discontinuity network simulation method and its accuracy comparison," Chinese Journal of Rock Mechanics and Engineering, vol. 31, no. 4, pp. 822-833, 2012.

[25] D. Xu, R. S. Chen, H. Li et al., "Study for roughness of rock joints in fractal research based on panoramic borehole images," Journal of Engineering Geology, vol. 23, no. 5, pp. 918-923, 2015.

[26] Y. Z. Liu, J. L. Sheng, X. R. Ge et al., "Evaluation of rock mass quality based on fractal dimension of rock mass discontinuity distribution," Rock and Soil Mechanics, vol. 28, no. 5, pp. 971-975, 2007. 